and the outer rexine covering on the backs of the railway seats, where the fire in this case began, might be omitted. It is evident that the main lessons of this fire require to be studied by the travelling public in general rather than by the railway companies or their employees. The carelessness habitually displayed by many passengers in the disposal of matches and cigarette ends is quite inexcusable; nevertheless, the provision of more and larger 'ash trays' might be considered.

\section{Making Light for To-morrow}

THE Electrician of July 4 quotes Mr. S. G. Hibben, director of applied lighting to the Westinghouse Lamp Division, as attributing most of the very rapid progress being made in developing illuminants to the influence of the large 'fairs' recently held in the United States. Each exhibition has been identified with some new and often radical means of producing light. The Panama-Pacific Exposition of 1915 ushered in the use of tungsten filament lamps of large wattage for exterior floodlighting, and coloured beams from carbon-are searchlights. In 1926 the Philadelphia Sesqui-Centennial Exposition presented colourcoated incandescent filament lamps with spirally coiled filaments surrounded by inert nitrogen and argon, in sizes down to and including the commercial $60-$ w. lamp. High voltage ( 10,000 volt range) neon and mercury tubing for architectural decoration were also used. The high-intensity mercury vapour lamps were publicly introduced into the United. States at the Chicago Century of Progress Exposition in 1933.

Noteworthy above all others, the New York World's Fair of 1939-40 introduced in that country the radically new and efficient fluorescent lamps. In addition, there were also introduced new sizes of mercury vapour lamps for the illumination of foliage, the production of short-wave visible colours for underwater fountain lighting, new projector lamps, and the popularly termed 'black-light' lamps or longwave ultra-violet illuminants. The latter of these gave a wide variety of fluorescent effects. Whilst attention is naturally focused on the new or unusual illuminants, it has to be remembered that the familiar incandescent lamp is, and for many years to come will be, the basic, most commonly used lamp for work requiring light primarily. More precise manufacturing methods and lower costs now give the purchaser two and a half times as much light for the same money, as compared with 1928.

\section{Seismological Data from India}

VALUABLE seismological data is contained in the Seismological Bulletin of the Government of India Meteorological Department for the period JanuaryMarch 1940, published under the direction of Dr. C. W. B. Normand. Interpretations of the seismograms obtained at the observatories at Agra, Bombay, Calcutta, Colombo, Dehra Dun, Hyderabad and Kodaikanal are given in considerable detail, and it is pleasing to note that J. H. Sil at Poona has again collected non-instrumental reports from voluntary observers. At the Upper Air Observatory at Agra, ninety-four earthquakes and tremors were recorded instrumentally during the quarter, and in each case there are given the type of wave with its arrival time, occasionally its period and amplitude, together with the estimated epicentral distance and depth of focus. The deepest focus shock recorded was apparently one approximately $200 \mathrm{~km}$. deep estimated by the Brunner Chart, on March 28, at an estimated epicentral distance of 4,135 km. The other observatory reports are along similar lines. Fifteen earthquakes were recorded by voluntary observers. Three of these reached intensity 7 on the Rossi-Forel scale. These were at Srinagar on January 26, Gauhati on February 13 and Drosh on March 19, the latter also being recorded with lesser intensities at Kabul, Peshawar and Srinagar.

\section{Announcements}

The Bisset-Hawkins Medal of the Royal College of Physicians has been awarded to Sir Frederick Menzies for his work as chief medical officer of the London County Council, and the Baly Medal has been awarded to Prof. Edgar Allen, of Yale University, for his work on ostrogens.

Prof. Jean Perrin, formerly professor of physical chemistry in the University of Paris, has been invited to become visiting lecturer at Wilson College, Chambersburg, U.S.A., during the academic year 1941-42.

THE South African Institute for Medical Research in Johannesburg is about to undertake the manufacture of yellow fever vaccine under the directions of Dr. G. M. Findlay of the Wellcome Research Institute of London.

THE American Society for X-Ray and Electron Diffraction, plans for which were announced in Science of May 23, starts its existence with a charter membership of 124. The officers elected for 1941 are : President, Dr. M. L. Huggins, of the Eastman Kodak Company; Vice-President, Prof. B. E. Warren, of the Massachusetts Institute of Technology ; SecretaryTreasurer, Dr. George Tunell, of the Geophysical Laboratory, Washington, D.C.

THE British Association's Division for the Social and International Relations of Science is arranging a meeting to be held, if circumstances allow, on September 26, 27 and 28. Various subjects under the general heading of "Science and World Order" will be dealt with. The first day's session will take place, by kind permission, in the theatre of the Royal Institution, Albemarle Street, London, and those of the second and third days, it is hoped, at the Rothamsted Experimental Station, Harpenden.

Dr. Kenneth M. Smrth writes: "In a recent review entitled 'Insects and Plant Diseases' (NATURE, July 19 , p. 65), through an error in proof-reading, it was made to appear that 1801 was the date of the first discovery of bacteria as a cause of plant disease. This should, of course, be 1881, eleven years before the first demonstration of a virus by Iwanowsky in 1892." 